\section{Commentary: Isolated absence gives new meaning to total absence}

\author{
Ibrahim Abdullah, MD, and Zohair Al-Halees, MD
}

In this issue of JTCVS Techniques, Inoue and colleagues ${ }^{1}$ from Japan present a fascinating rare case of a 66-yearold woman who was hospitalized for heart failure due to severe mitral regurgitation. Her echocardiogram also showed a remarkably dilated right ventricle with significant dilatation of the pulmonary arteries. She underwent a mechanical mitral valve replacement, and inspection of her pulmonary valve revealed a congenitally absent single pulmonary valve leaflet. She subsequently underwent a pulmonary valve repair with bovine pericardial patch reconstruction of the absent leaflet and a reduction pulmonary arterioplasty. Repeat echocardiography 1 year later demonstrated no pulmonary stenosis, mild pulmonary insufficiency, and continued dilatation of the pulmonary trunk. Given the pulmonary findings of this case, do we need to reconsider our conceptual paradigm of the absent pulmonary valve syndrome associated with tetralogy of Fallot?

In tetralogy of Fallot with absent pulmonary valve, a large ventricular septal defect is universally present along with usual absence of the ductus arteriosus, resulting in equalization of ventricular pressures and hence elevation of pulmonary artery pressures. The significantly elevated pulmonary artery pressures, coupled with the to-and-fro flow into the pulmonary arteries, is thought to be the etiology of the significant pulmonary artery dilatation and often underdevelopment of the airways due to pulmonary artery impingement. However, is that what truly causes the pulmonary artery dilatation and its untoward effects?

In this report, the patient had no ventricular septal defect, and catheterization data showed a mean pulmonary artery pressure of $14 \mathrm{~mm} \mathrm{Hg}$. So, where does the significant

\footnotetext{
From the Department of Pediatric Cardiac Surgery, King Faisal Specialist Hospital \& Research Center, Riyadh, Saudi Arabia.

Disclosures: The authors reported no conflicts of interest.

The Journal policy requires editors and reviewers to disclose conflicts of interest and to decline handling or reviewing manuscripts for which they may have a conflict of interest. The editors and reviewers of this article have no conflicts of interest.

Received for publication Aug 26, 2021; revisions received Aug 26, 2021; accepted for publication Sept 1, 2021; available ahead of print Sept 7, 2021.

Address for reprints: Ibrahim Abdullah, MD, Department of Pediatric Cardiac Surgery, King Faisal Specialist Hospital \& Research Center, MBC 16, Heart Centre, King Faisal Specialist Hospital \& Research Center, Al Mathar Ash Shamali, Riyadh, Saudi Arabia 11564 (E-mail: iabdullah1234@gmail.com).

JTCVS Techniques 2021;10:439-40

2666-2507

Copyright (c) 2021 The Author(s). Published by Elsevier Inc. on behalf of The American Association for Thoracic Surgery. This is an open access article under the CC BY-NC-ND license (http://creativecommons.org/licenses/by-nc-nd/4.0/).

https://doi.org/10.1016/j.xjtc.2021.09.012
}

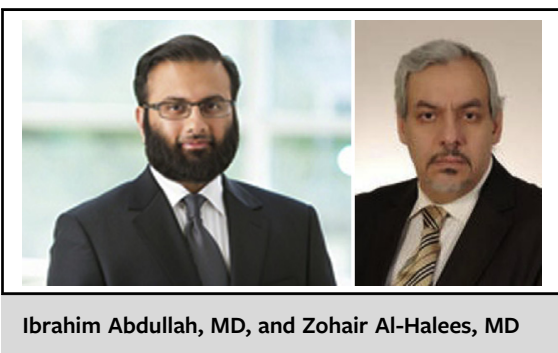

\section{CENTRAL MESSAGE \\ Congenital absence of a single pulmonary valve cusp offers re- newed insight into the absent pulmonary valve syndrome.}

pulmonary artery dilatation come from with such low pressures? Is there another mechanism? Although the authors performed a reduction pulmonary arterioplasty, they report no biopsy findings of the pulmonary arteries. This case leads one to believe that perhaps the absence of a pulmonary valve or pulmonary valve leaflet is likely associated with inherent architectural changes in the pulmonary arteries that leads to significant dilatation irrespective of pulmonary arterial pressures. In fact, Rabinovitch and colleagues ${ }^{2}$ performed histologic examinations of a series of patients with bronchial compression and absent pulmonary valve syndrome and found that the elastic laminae of the pulmonary arteries were thickened and fragmented. Perhaps the mere absence of a pulmonary valve leaflet implies significant connective tissue disease. This, coupled with abnormal flow dynamics, may be a leading contributing factor to the significant pulmonary arterial dilatation. Although not presented, a biopsy and magnetic resonance imaging flow study of the pulmonary arteries may be helpful in understanding this phenomenon in such a rare case.

Regardless of the etiology of the pulmonary arterial dilatation, the authors chose to reconstruct the missing pulmonary valve leaflet despite performing a mechanical mitral valve replacement. One may argue that with recent reports indicating good long-term durability, a mechanical pulmonary valve may be an attractive option in a patient who is already anticoagulated with a mechanical mitral valve. ${ }^{3}$ Although the choice of reconstruction material may be debatable, we agree with the authors' approach. At 1 year, their reconstructed pulmonary valve leaflet reportedly continues to function well, and with the recent application of aortic neocuspidization techniques to the pulmonary valve, more options exist. ${ }^{4}$

The authors ought to be congratulated for reporting this rare case, which offers renewed insight into a rare disease. 


\section{References}

1. Inoue S, Mori A, Iida Y, Oka H. Isolated congenital absence of a single pulmonary valve cusp. J Thorac Cardiovasc Surg Tech. 2021;10:433-6.

2. Rabinovitch M, Grady S, David I, van Praagh R, Sauer U, Buhlmeyer K, et al. Compression of intrapulmonary bronchi by abnormally branching pulmonary arteries associated with absent pulmonary valves. Am J Cardiol. 1982;50:804-13.
3. Dehaki MG, Al-Dairy A, Rezaei Y, Omrani G, Jalali AH, Javadikasgari H, et al Mid-term outcomes of mechanical pulmonary valve replacement: a singleinstitutional experience of 396 patients. Gen Thorac Cardiovasc Surg. 2019;67: 289-96.

4. Baird CW, Chavez M, Friedman KG. Pulmonary valve reconstruction using the Ozaki leaflet reconstructive techniques. Ann Thorac Surg. 2021;111:e19-21. 